\title{
OVERVIEW KEPUASAN PELANGGAN: STUDI KASUS PELAYANAN RIJSTAFFEL DI RESTORAN OASIS
}

\author{
Maria Pia Adiati; Agung Gita Subakti \\ Hotel Management Department, Faculty of Economics and Communication, BINUS University \\ Jln. K.H. Syahdan No. 9, Kemanggisan, Palmerah, Jakarta Barat 11480 \\ mia_pia_adiati@hotmail.com; agsubakti@yahoo.com
}

\begin{abstract}
Rijstaffel service is not common found in fine dining restaurant in Indonesia. Oasis Restaurant in Jalan Raden Saleh, Jakarta, is a restaurant that is consistent in serving rijstaffel menu. The objective of this research is to analyze the level of consumer satisfaction and service quality in rijstaffel service at Oasis Restaurant. Research used qualitative method with library research by analyzing the questionnaire distributed by Oasis on Mei 2013 with 21 respondents. The result is the indicators which got excellence point were service, ambience, value for money, food; and the indicator which got good point was home band and vocal group.
\end{abstract}

Keywords: rijstaffel, consumer satisfaction, service quality

\begin{abstract}
ABSTRAK
Restoran fine dining yang menggunakan pelayanan berbentuk rijstaffel tidak lazim ditemukan di Indonesia. Restoran Oasis, di Jln Raden Saleh, Jakarta, merupakan restoran yang sejak 1976 hingga kini tetap konsisten dalam menyajikan menu rijsttafel. Penelitian bertujuan untuk menganalisis tingkat kepuasan konsumen dari kualitas produk yang dihasilkan dan kualitas pelayanan dalam pelayanan rijstaffel di Restoran Oasis. Metode yang dipakai adalah kualitatif dengan studi pustaka dan analisis kuesioner Oasis pada Mei 2013 dengan total 21 responden. Hasil yang didapat adalah indikator yang diberikan excellence pada indikator service, ambience, value for money, food. Sementara untuk indikator home band dan vocal group, para pengunjung mayoritas memilih good.
\end{abstract}

Kata kunci: rijstaffel, kepuasan pelanggan, kualitas layanan 


\section{PENDAHULUAN}

Restauran fine dining yang menggunakan pelayanan berbentuk rijstaffel memang tidak lazim ditemukan di Indonesia karena pelayanan rijstaffel itu sendiri tidak lazim digunakan dalam tipe pelayanan restoran. Pelayanan yang umumnya ditemui di restoran fine dining adalah French service atau bahkan Russian service. Akan tetapi, pada restoran di Indonesia dan Belanda ada jenis pelayanan yang lain, yaitu rijstaffel.

Restoran Oasis, yang terletak di Jln. Raden Saleh, Jakarta, merupakan restoran yang hingga kini tetap konsisten dalam menyajikan menu rijsttafel. Menu yang telah ada sejak restoran ini dibuka pada 1976. Penyajian satu set menu dari berbagai daerah nusantara yang memiliki sejarah panjang itu memang menjadi andalan. Cara menyantap nasi putih ditemani berbagai jenis lauk-pauk yang setiap jenis lauknya dibawa oleh seorang pramusaji ini sudah berkembang di Indonesia sejak zaman kolonial. Makin banyak lauk terhidang, makin banyak pramusaji yang melayaninya. Seolah-olah, rijsttafel tak ubahnya hidangan fine dining ala Indonesia.

Menu rijsttafel di Oasis terdiri dari 12 jenis hidangan. Hidangan-hidangan tersebut terdiri dari hidangan pembuka yang biasanya merupakan sup dari salah satu daerah Nusantara seperti sup Kedu; makanan utama seperti daging, ikan, dan sayur; makanan penutup; serta tentunya sambal. Yang menarik adalah rijsttafel yang disajikan tematik, yaitu jenis makanan yang disajikan tiap bulan berbeda dan merupakan hidangan dari nusantara. Dalam laman website ditampilkan bahwa terdapat 6 rijstaffel menu cycle dengan 1 rijstaffel VIP menu serta menu Bali rijstaffel. Wawancara dengan Ibu Landa selaku Kepala Koki, pada acara tertentu seperti Hari Kartini dan 17 Agustus resetoran mengeluarkan menu rijstaffel spesial yang berbeda dengan menu biasanya.

Menurut wawancara dengan General Manager Restoran Oasis yaitu Bapak O’om Mucharam: "Sebagian besar tamu yang datang ke Oasis, hampir 90\% terutama yang menikmati pelayanan rijstaffel adalah orang asing.” Bapak O’om juga mengakui bahwa orang Indonesia memang tidak familiar dengan pelayanan ala rijstaffel ini. Masih menurut Bapak O’om, "Hal ini berbeda kondisinya dengan orang-orang Belanda yang lebih familiar dengan pelayanan ala rijstaffel, sementara di Indonesia terbatas hanya ada di Oasis, Kunskring Palais (Jakarta), Rijstaffel Resto (Bandung), dan beberapa restoran di Bali seperti di Dulang Restaurant (St. Regis Resort). Sementara menu-menu rijstaffel dapat ditemukan di Restoran berbintang seperti di Spandershoeve di Hilversum, Anak Depok di Den Dolder, dan beberapa kota lainnya."

Tujuan penelitian ini adalah sebagai berikut. Pertama, menganalisis tingkat kepuasan konsumen dari kualitas produk yang dihasilkan dalam pelayanan rijstaffel di Restoran Oasis, Jakarta. Kedua, menganalisis tingkat kepuasan konsumen dari pelayanan dalam pelayanan rijstaffel di Restoran Oasis, Jakarta.

\section{METODE}

Penelitian menggunakan metode kualitatif dengan studi pustaka, kuesioner hasil survei restoran Oasis bulan Mei 2013, dan wawancara. Penelitian tidak untuk mengukur seberapa kuat pengaruh kualitas pelayanan terhadap kepuasan pelanggan. Penelitian hanya menganalisis kualitas pelayanan rijstaffel di Restoran Oasis dan komentar pengunjung terhadap pelayanannya berdasarkan kuesioner Restoran Oasis. Penelitan sebelumnya menganalisis pengaruh kualitas layanan terhadap kepuasan konsumen restoran (Griselda \& Panjaitan, 2007) dan menganalisis pengaruh kualitas pelayanan terhadap loyalitas pelanggan restoran (Sari, 2011). 


\section{HASIL DAN PEMBAHASAN}

Industri restoran (food and beverage service) merupakan salah satu dari industri jasa. Di Indonesia industri restoran dimasukkan ke industri pariwisata menurut UU Kepariwisataan No 19 tahun 2009. Karakter industri jasa berbeda dengan industri manufaktur. Menurut Kotler (dalam Supranto, 2001:227-228) karakter industri jasa terbagi atas 4 karakter sebagai berikut.

Pertama, suatu jasa mempunyai sifat tidak berwujud (intangible), tidak dapat dirasakan, dan dinikmati sebelum dibeli oleh konsumen. Misalnya telepon dalam jasa telekomunikasi, pesawat dalam jasa angkutan udara, makanan dalam jasa restoran, dan sebagainya. Kedua, pada umumnya jasa yang dihasilkan dan dirasakan pada waktu bersamaan (inseparibility/tidak dapat dipisahkan). Apabila dikehendaki oleh seorang untuk diserahkan kepada pihak lainnya, dia akan tetap merupakan bagian dari jasa tersebut. Dengan demikian kunci keberhasilan bisnis jasa terdapat pada proses rekrutmen, kompensasi, pelatihan, dan pengembangan karyawan. Ketiga, jasa senantiasa mengalami perubahan (variability/variasi). Hal tersebut tergantung dari siapa penyedia jasa, penerima jasa, dan kondisi jasa tersebut diberikan. Keempat, daya tahan suatu jasa tergantung suatu situasi yang diciptakan oleh berbagai faktor (perishability/tidak tahan lama/mudah lenyap). Kursi kereta api yang kosong, kamar hotel yang tidak dihuni akan hilang begitu saja karena tidak dapat disimpan untuk dipergunakan di waktu yang lain.

Sementara itu, dimensi kualitas jasa, yang dalam hal ini adalah kualitas pelayanan, mempunyai 5 faktor yang menentukan kualitas jasa. Menurut Irawan (2002:37-40), faktor-faktor pendorong kepuasan konsumen terbagi atas lima bagian. Faktor pertama, kualitas produk. Konsumen merasa puas jika produk yang telah dibeli dan digunakan memiliki kualitas yang baik. Sebagai contoh, konsumen akan merasa puas terhadap televisi yang dibeli apabila mengahasilkan gambar dan suara yang baik, awet atau tidak cepat rusak, memiliki banyak fasilitas, tidak ada gangguan, dan desain yang menarik.

Faktor kedua, harga. Untuk konsumen yang sensitif, biasanya harga yang murah adalah sumber kepuasan yang penting karena mereka akan mendapatkan nilai uang yang tinggi, komponen harga ini relatif tidak penting bagi mereka yang tidak sensitif terhadap harga. Bagi mereka yang tidak peduli dengan harga, mereka lebih menyukai harga yang sedikit mahal namun kualitasnya baik daripada harga yang murah tetapi kualitasnya tidak sesuai dengan keinginan. Jadi persaingan dalam harga akan mendapatkan perhatian konsumen sepanjang kualitas barang adalah sama. Kualitas produk dan harga sering kali tidak mampu menciptakan keunggulan bersaing dalam hal kepuasan konsumen. Kedua aspek ini relatif mudah ditiru dengan teknologi yang hampir standar, setiap perusahaan biasanya mempunyai kemampuan untuk menciptakan kualitas produk yang hampir sama dengan para pesaing. Oleh karena itu, banyak perusahaan yang lebih mengandalkan aspek yang ketiga yaitu service quality.

Pada faktor ketiga, untuk memuaskan pelanggan, suatu perusahaan hendaknya terlebih dahulu harus dapat memuaskan karyawan. Hal tersebut dimaksudkan agar kualitas produk yang dihasilkan tidak rusak dan pelayanan kepada pelanggan dapat diberikan lebih baik. Jika karyawan merasa puas, akan lebih mudah bagi mereka untuk menerapkan kepada pelanggan rasa puas itu. Dalam menentukan suatu kualitas jasa (Umar, 2000:38-40) terdapat lima dimensi yang sangat memengaruhi. Dimensidimensi tersebt adalah sebagai berikut.

Keandalan (realibility), yaitu kemampuan untuk memberikan pelayanan yang sesuai dengan janji yang ditawarkan. Keresponsifan (responsiveness), yaitu respons atau kesigapan karyawan dalam membantu konsumen dan memberikan pelayanan yang cepat dan tanggap. Responsiveness meliputi kesigapan karyawan dalam melayani konsumen, kecepatan karyawan dalam menangani transaksi, dan cara penanganannya. Keyakinan (assurance) meliputi kemampuan karyawan atas pengetahuan 
terhadap produk secara tepat, kualitas keramah-tamahan, perhatian dan kesopanan dalam memberikan pelayanan keterampilan dalam memberikan informasi, kemampuan dalam memberikan keamanan dalam memanfaatkan jasa yang ditawarkan, dan kemampuan dalam menanamkan kepercayaan konsumen terhadap perusahaan. Empati (emphaty), yaitu perhatian secara individual yang diberikan perusahaan kepada konsumen seperti kemudahan untuk menghubungi perusahaan, kemampuan karyawan untuk berkomunikasi dengan konsumen, dan usaha perusahaan untuk memahami keinginan dan kebutuhan konsumennya. Berwujud (tangible) meliputi penampilan fasilitas fisik seperti gedung, ruang makan, ruang front office, tersedianya lahan parkir, kebersihan, kerapihan dan kenyamanan ruangan, kelengkapan peralatan komunikasi dan penampilan karyawan.

Kemudian, faktor keempat, emotional factor, relatif penting. Kepuasan pelanggan timbul pada saat ia sedang mengonsumsi produk makanan tertentu. Hal ini disebabkan merek produk makanan tersebut sudah tercipta dengan baik, baik dari segi kualitas makanan, harga yang tidak murah—-harga mahal identik dengan kualitas produk yang tinggi dan sebaliknya, serta pelayanan yang diberikan. Faktor terakhir adalah kemudahan. Konsumen akan makin puas apabila tempat mudah dicapai dan juga nyaman.

Dengan mengetahui kelima faktor ini, tentulah tidak cukup bagi perusahaan untuk merancang strategi dan program peningkatan kepuasan konsumen. Lebih lanjut, penjelasan untuk kualitas jasa dalam industri restoran secara lebih spesifik diungkapkan oleh Stevens, Knutson, dan Patton dalam Markovic et al. (2010):

\begin{abstract}
"In the restaurant industry, tangibles refer to a restaurant's physical design, appearance of staff and cleanliness. Reliability involves freshness and temperature of the food, accurate billing and receiving ordered food. Responsiveness in restaurants relates to staff assistance with the menu or wine list or appropriate and prompt response to customers' needs and requests. Assurance means that restaurant customers should be able to trust the recommendations of staff, feel confident that food is free from contamination and be able to say any concern without fear. Finally, empathy refers to providing personalized attention to customers by anticipating special dietary requirements or by being sympathetic towards customers'problems."
\end{abstract}

Kotler (1997:38) menjelaskan alat-alat untuk melacak dan mengukur kepuasan konsumen. Pertama, sistem keluhan dan saran. Sebuah perusahaan yang berfokus pada pelanggan mempermudah pelanggannya untuk memberi saran dan keluhan. Dalam menyampaikan saran dan keluhan dapat melalui nomor telepon gratis untuk memaksimalkan kemudahan yang diharapkan oleh para pelanggan. Arus informasi ini menyediakan banyak gagasan yang baik bagi perusahaan-perusahaan ini dan memungkinkan mereka bertindak lebih cepat untuk menyelesaikan masalah. Kedua, survei kepuasan pelanggan. Penelitian menunjukkan bahwa bila para pelanggan yang tidak puas dengan satu dari setiap empat pembelian, kurang dari 5\% pelanggan yang tidak puas akan mengeluh. Karenanya, perusahaanperusahaan tidak dapat menggunakan banyaknya keluhan sebagai ukuran kepuasan pelanggan. Perusahaan-perusahaan yang responsif memperoleh ukuran kepuasan pelanggan secara langsung dengan melakukan survei berkala.

Pada kuesioner yang dilakukan Restoran Oasis, indikator yang ditanyakan adalah ambience, service, food, value for money, home band, dan vocal group dengan responden sebanyak 21 orang. Menurut Bapak O’om, selama periode survei, hanya 21 orang yang berminat mengisi kuesioner. Hal ini disebabkan tipikal tamu yang kebanyakan VIP, sehingga mereka kurang tertarik untuk mengisi survei.

Hasil dari kuesioner adalah sebagai berikut. Dari hasil demografi (Gambar 1) terlihat bahwa 17 orang adalah laki-laki dan 6 orang adalah perempuan. Menurut hasil pengamatan dan hasil wawancara, kebanyakan yang datang adalah tamu-tamu bisnis dan bukan keluarga. Hal ini yang menyebabkan lebih banyak laki-laki yang menjadi pengunjung. 


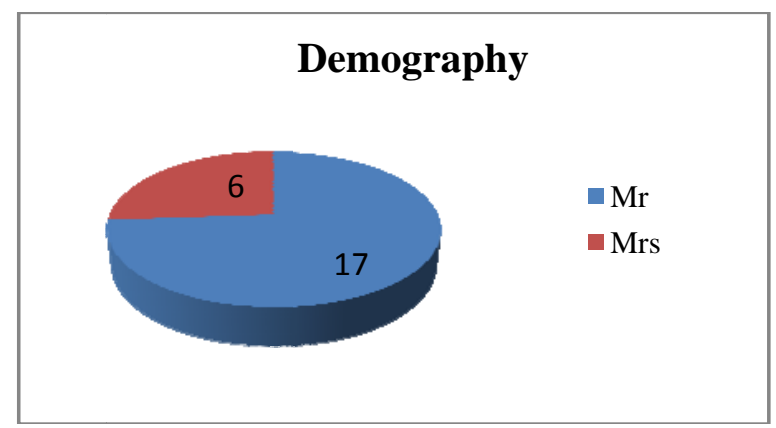

Gambar 1 Demografi responden

Dari 21 pengunjung, terlihat mayoritas adalah tamu warga negara asing (Gambar 2) dengan pembagian sebagai berikut. Dari Jepang 8 orang, Malaysia 2 orang, Jerman, China, Amerika, dan Australia masing masing 1 orang. Warga negara Indonesia sebanyak 7 orang. Melihat kondisi bahwa banyaknya warga negara asing yang menjadi tamu di Oasis, hal ini disebabkan karena penyajian rijstaffel belum familiar bagi kalangan orang Indonesia dan juga harga set menu rijstaffel tidak murah (sekitar Rp600 ribu). Selain itu, dengan karakter bahwa pengunjung tamu bisnis, bisa digambarkan bahwa warga Indonesia yang menjadi host bagi tamu warga negara asing yang sedang berbisnis di Indonesia dijamu menikmati makanan Indonesia dengan penyajian fine dining ala rijstaffel di Oasis.

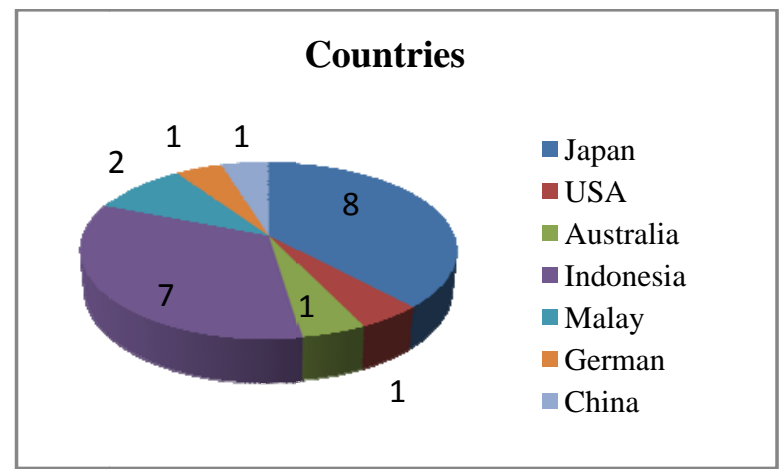

Gambar 2 Asal Negara

Selanjutnya dibahas indikator dalam kuesioner yaitu menyangkut kepuasan pelanggan. Menurut Irawan (2002) indikator kepuasan pelanggan adalah kualitas produk. Di Oasis kualitas produk yang utama adalah makanan. Dari hasil survei terlihat bahwa 13 orang menyatakan Food Excellence dan 8 orang adalah Good (Gambar 3). Semua menyatakan bahwa kualitas makanan yang ditawarkan adalah baik dan tidak mengecewakan. 


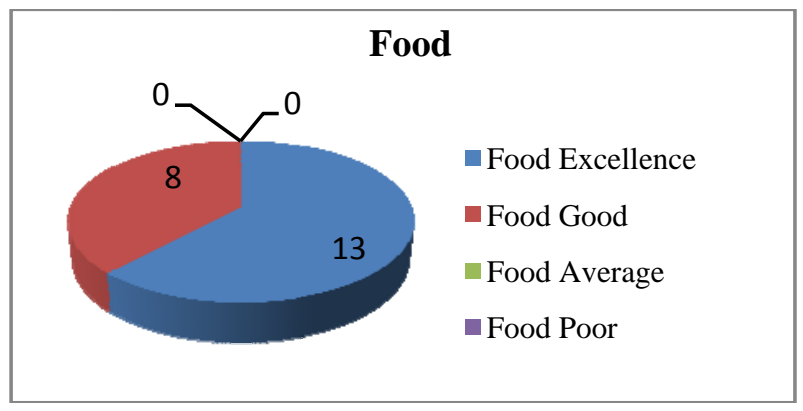

Gambar 3 Kualitas Produk

Dari hasil pengamatan Oasis menawarkan menu Indonesia yang otentik dan modern. Oasis juga mempunya beberapa menu cycle untuk pelayanan rijstaffel sehingga tidak membosankan. Dengan 6 cycle menu serta 1 VIP rijstaffel menu dan menu khusus pada hari Kartini dan Hari Kemerdekaan menjadi menunya beragam.

Indikator kepuasan pelanggan yang lain yaitu harga (value for money). Dengan harga pelayanan rijstaffel sekitar Rp600 ribu, nilai dan pengalaman yang didapatkan sebanding dengan harganya karena dari 21 orang, 15 orang mengatakan excellence, sementara 4 orang mengatakan good dan 2 orang menyatakan average (Gambar 4). Harga tampaknya bukan menjadi kendala utama karena jika dilihat dari demografi responden, mayoritas adalah warga negara asing yang ingin mencoba hal yang baru dan harga bukan yang menjadi masalah utama.

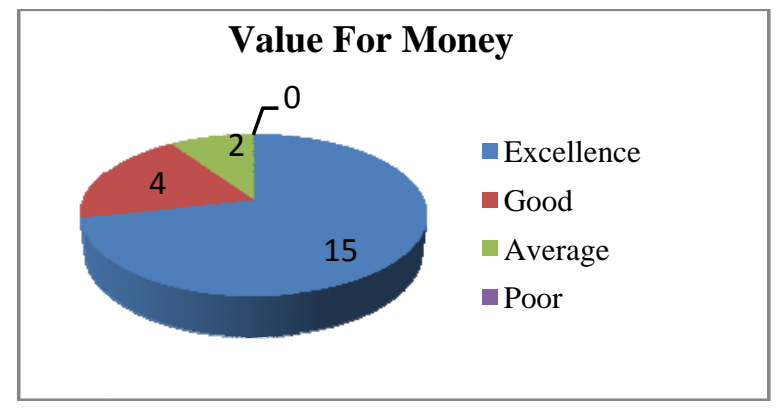

Gambar 4 Value for Money

Indikator pelayanan memang tidak menjabarkan secara rinci mengenai dimensi dari kualitas pelayanan. Akan tetapi, hasil wawancara dengan pihak Oasis mendapatkan hasil bahwa dalam poin pelayanan ini jika dibandingkan dengan dimensi kepuasan pelanggan adalah reliability dan responsiveness. Definisi reliability adalah staf mampu memberikan pelayanan yang sesuai seperti yang dijanjikan. Sementara definisi responsiveness adalah staf mampu menanggapi kemauan konsumen dengan cepat.

Dari hasil kuesioner yang disebar, 21 responden semuanya menyatakan bahwa pelayanan yang diberikan adalah excellence (Gambar 5). Kesan tamu terhadap pelayanan dapat dilihat dari guest comments yang dibagi bersamaan dengan kuesioner. Komentar mengenai pelayanannya adalah "very good service," "very nice experience," "excellent service," "good food, good service," "everything was great wold definitely came back again next time we're in Jakarta," "service is very good, I want to have Indonesian song because this is traditional Indonesian Restaurant," "Staff are so friendly and helpful, its quite traditional restaurant. We are really happy to see smilling faces in traditional 
clothes. Thank you so much for everything and good hospitality." Dari komentar yang diberikan, para tamu sangat puas dengan pelayanan rijstaffel yang diberikan dan bahkan ada yang berniat akan kembali lagi jika ia ke Jakarta. Terlihat juga staf di Oasis sangat ramah dan mau membantu.

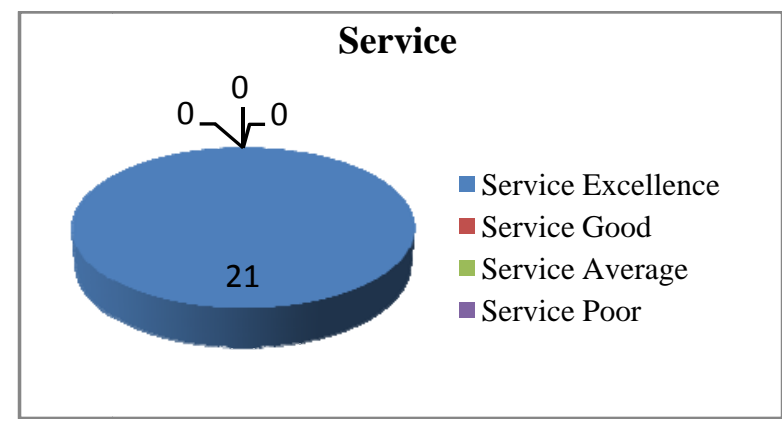

Gambar 5 Service

Indikator selanjutnya dalam kuesioner adalah ambience. Dalam wawancara dengan Bapak O’Om, yang dimaksud dengan ambience adalah suasana yang dirasakan dan keseluruhan interior serta penampilan yang dilihat tamu. Suasana dan interior ini mendukung keseluruhan pelayanan rijstaffel karena gedung restoran Oasis sudah berdiri sejak 1928. Interior didekorasi dengan ornamen asli Indonesia seperti topeng dari berbagai daerah serta perisai dari Papua. Table set up yang dipakai untuk penyajian rijsftaffel tetap ditata secara elegan.

Dari hasil kuesioner, terlihat 16 responden menjawab restoran Oasis mempunyai ambience "excellence" dan 5 orang menjawab "good" (Gambar 6). Keseluruhan responden menjawab ambience di Oasis termasuk baik dan tidak mengecewakan. Komentar pengunjung mengenai ambience adalah,"Excellent ambience, service, food and value for money", "interior desain kuno dan sangat menarik".

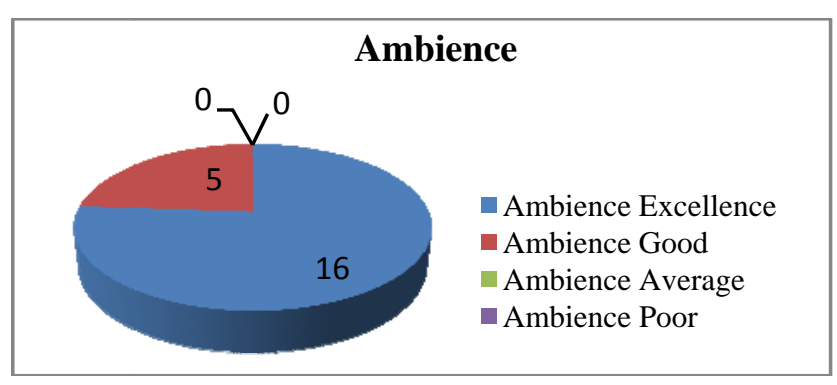

Gambar 6 Ambience

Dimensi lain dari kualitas pelayanan adalah tangible atau yang nampak dan dapat disentuh. Karena interior sudah masuk dalam indikator ambience serta penampilan seragam staff masuk dalam indikator service serta kualitas produk masuk dalam indikator food, hal-hal yang dapat dilihat dan disentuh menurut kuesioner yaitu indikator home band dan vocal group. Setiap malam selalu ada penampilan musik secara langsung baik berupa vocal group maupun home band yang membawakan lagu-lagu daerah Indonesia maupun lagu asing jika ada permintaan dari tamu. 
Berdasarkan hasil kuesioner, baik untuk indikator vocal group maupun home band, dari 21 responden, 10 orang menjawab excellence dan 11 orang menjawab good (Gambar 7 dan Gambar 8). Komentar dari tamu mengenai musik adalah, "music and service is very good." Ada juga saran dari tamu," I want to have Indonesian song because this is traditional Indonesian Restaurant," dan "the music is too loud." Walaupun ada saran seperti itu dan hasil kuesioner menunjukkan penampilan home band dan vocal group adalah good dan excellence, secara keseluruhan penampilan vocal group maupun home band menghibur tamu. Penampilan vocal group dan home band juga menambah pengalaman berkunjung para tamu karena mereka membawakan lagu daerah Indonesia dan penampilannya pun tidak mengecewakan.

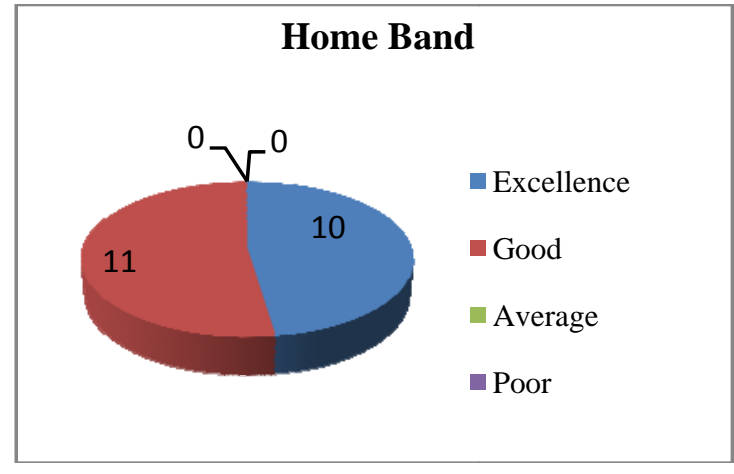

Gambar 7 Home Band

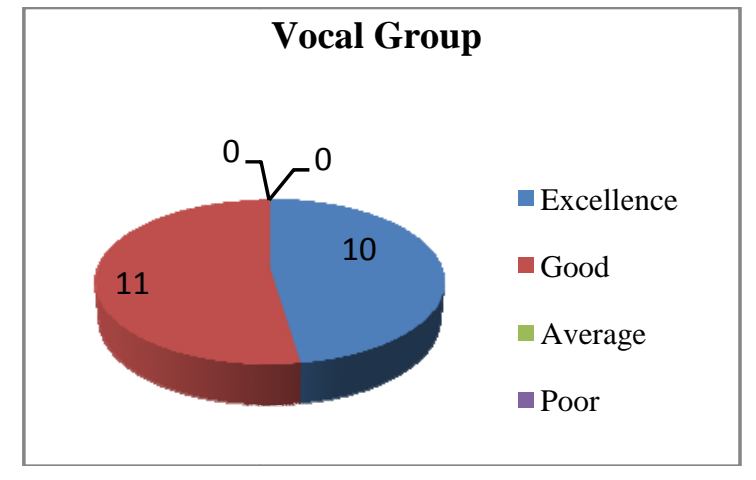

Gambar 8 Vocal Group

\section{SIMPULAN}

Melihat hasil kuesioner yang dibagikan pihak Oasis, maka terlihat bahwa keseluruhan mayoritas pengunjung memilih excellence pada indikator service, ambience, value for money, dan food. Sementara untuk indikator home band dan vocal group, para pengunjung mayoritas memilih good. Jika dilihat semua indikator berada pada area good dan excellence, para pengunjung yang dibagikan kuesioner merasa puas dengan keseluruhan pelayanan pada rijstaffel service di Oasis. Beberapa menyatakan bahwa mereka akan kembali lagi ke Oasis, serta ada seorang pengunjung yang mengatakan, "Great overall experience will be great to bring guest." Dari komentar yang masuk, para pengunjung juga mengharapkan bahwa Oasis dapat mempertahankan kualitas makanan, penyajian, dan pelayanan. Simpulan lain adalah pengunjung di Oasis mayoritas warga negara asing, hanya ada 7 warga negara Indonesia dari 21 orang responden.

Kendati demikian, Oasis juga harus memerhatikan saran dari tamu mengenai pemilihan lagu oleh home band ataupun vocal group. Tamu menyarankan agar restoran menyajikan lebih banyak lagu bahasa Indonesia/lagu daerah. Selain itu, mereka menyrankan agar volume musik dikurangi karena terlalu keras. Saran untuk restoran Oasis juga adalah jika ingin membuat kuesioner lagi, detail dari indikator bisa diperjelas. Misalnya, indikator service yang tidak dijelaskan apakah service hanya untuk pelayanan rijstaffel atau keseluruhan staf mulai dari pemesanan meja hingga mereka selesai menikmati makanan di Oasis. Pengalaman yang unik saat tamu menikmati hidangan dan pelayanan ala rijstaffel menjadi kunci utama para tamu sangat menikmati pelayanan dari restoran Oasis. Pada masa mendatang, keunikan dan pengalaman menikmati makanan adalah hal yang dicari pelanggan, bukan hanya dari soal rasa dan harga. Hal ini seperti dikutip dari Wishna dalam Markovic et al (2020) yang mengungkapakan: 
"Wishna predicted that, in the future,customers will be more sophisticated in their dining decisions mainly because of their willingness to expand their dining horizons and try new things. Customers will seek new dining experiences that will satisfy their ever-changing expectations. Thus, it is important to know, understand and meet customers' expectations."

Dengan kondisi bahwa masih sedikit orang Indonesia yang mengetahui pelayanan rijstaffel, maka pihak Oasis disarankan bisa terus mensosialisaikan kekayaan budaya rijstaffel. Selain ke perusahaan, pihak restoran bisa juga merambah ke dunia sekolah/akademis agar pelayanan rijstaffel makin dikenal. Pihak restoran bisa juga ke sekolah-sekolah perhotelan juga familiar dengan rijstaffel.

\section{DAFTAR PUSTAKA}

(2010). Retrieved November 30, 2014, from http://www.stregisbali.com/en/dulang-restaurant.

Anak Depok Indonesische Restaurant. (n.d.). Diakses 30 November 2014 dari http://www.anakdepok.nl/menukaart.html.

Griselda, G., \& Panjaitan, T. M. (2007). Analisis pengaruh kualitas layanan terhadap kepuasan konsumen Restoran Pulau Dua. Jurnal Manajemen: Derema, 2(1), 39-62.

Irawan, H. (2002). 10 Prinsip Kepuasan Pelanggan. Jakarta: Elex Media Komputindo.

Kotler, P. (1997). Manajemen Pemasaran: Perencanaan, Implementasi dan Kontrol (Jilid 1 dan 2). Jakarta: Prenhallindo.

Markovic, S., Raspor, S., \& Šegaric, K. (2010). Does Restaurant performance meet customers' expectations? An assessment of restaurant service quality using a modified DINESERV approach. Tourism and Hospitality Management , 181-195.

Spandershoeve. (n.d.). Diakses 30 November 2014 dari www.spandershoeve.nl.

St.Regis. (2011-2015). Diakses 30 November 2014 dari www.stregisbali.com/en/dulang-restaurant.

Supranto, J. (2001). Pengukuran Tingkat Kepuasan Pelanggan untuk Menaikkan Pangsa Pasar. Jakarta: Rineka Cipta.

Sari, L. E. (2011). Analisis Pengaruh Kualitas Pelayanan Jasa Restoran terhadap Loyalitas Pelanggan Sakana Japanese Restaurant di Delonix Hotel Kerawang. Skripsi (tidak diterbitkan). Fakultas Ekonomi Singaperbangsa, Karawang.

Umar, H. (2000). Riset Pemasaran dan Perilaku Konsumen. Jakarta: Gramedia Pustaka Utama. 